\title{
Workplace violence towards nurses: A reality from the Pakistani context
}

\author{
Rozina Karim Somani, Khurshid Khowaja \\ School of Nursing, Aga Khan University, Karachi, Pakistan
}

Correspondence: Rozina Karim Somani. Address: School of Nursing, Aga Khan University, Karachi, Pakistan. Telephone: 03-002-964-480. Email: Rozina.somani@aku.edu

Received: December 4, 2011

Accepted: March 28, 2012

Published: August 1, 2012

DOI : $10.5430 /$ jnep.v2n3p148

URL: http://dx.doi.org/10.5430/jnep.v2n3p148

\section{Abstract}

Workplace violence is a devastating issue worldwide. Incidents of workplace violence towards nurses are common in every healthcare setting. Nurses are more prone to workplace violence due to the nature of the tasks performed by them at healthcare settings. Lack of respect towards the nursing profession in the Pakistani society is a significant contributing factor in workplace violence towards nurses.

Workplace violence towards nurses is categorized in two types, psychological and physical violence and both these types of violence exist equally in different health care settings of Pakistan. There are many reported and unreported cases in which nurses experience rape, unwanted sexual deeds, workplace bullying, and physical violence from patients, their family members and other paramedical staff.

Limited work has been done to manage workplace violence at the health care settings in Pakistan. Incidents of violence towards nurses are yet under reported because of fear and more disrespect in the Pakistani society if reported formally. This is extremely important to design more effective strategies to assist nurses in dealing with workplace violence proficiently and competently. A Safe work environment will automatically attract nurses to remain in the nursing profession.

\section{Key words}

Workplace violence, Healthcare settings, Nursing profession, Safe work environment

\section{I ntroduction}

One novice registered nurse was working in a private ward of a tertiary care hospital when she encountered a workplace violence event. She was dealing with a 35 years old male patient in the evening shift, admitted with right knee fracture due to a road traffic accident. While performing the nursing tasks, she started feeling uncomfortable as the patient and his relatives were staring at her continuously. However, she tried to ignore the dirty gestures of the patient and his relatives and continued to perform the required tasks for the patient. On the second day of the patient's admission, she encountered the same situation, and while she was doing intravenous cannulation, the patient touched one of her private body part. This was intolerable for her; she immediately discontinued the procedure and tried to leave the patient's room. The patient's relative, who was in the room, became very aggressive; he took hold of her hand and used abusive language without being aware as to what had happened with her hand. He assumed that Ms. X was incompetent to perform the task; therefore, she 
was leaving the patient without completing the procedure. He forced her to complete the procedure or to send any senior staff. She became very nervous, she just said, "I am sending a senior person to you". This incident upset her a lot; it disturbed her mentally and physically and, eventually, she was ended up with post-traumatic stress syndrome.

Incidences of workplace violence towards nurses are common in every health care setting but they are more common in developing countries like Pakistan. However, they are not documented, reported, and published. Organizations' managements often face many challenges due to such incidences. This paper presents workplace violence towards nurses as a major issue in the context of health care settings in Pakistan. It will highlight the characteristics of violence that nurses face at the workplace, analyze problems from ethical and legal perspective with evidence and will discuss the physical and psychological consequences faced by the victims. Finally, some actions that could be taken at the individual, organizational, and society level to overcome similar issues will also be discussed.

Workplace violence is defined "an incident of aggression that is physical, sexual, verbal, emotional or psychological that occurs when nurses are abused, threatened or assaulted in circumstances related to their work" ${ }^{[1]}$. Moreover, Workplace violence has a considerable impact on the financial costs of an organization and an estimated cost in a year could be up to 4.2 billion dollars ${ }^{[2]}$.

Among all health care workers, nurses are at greatest risk for workplace violence because they work in a central position and interact with patients, families, doctors, and other paramedical staff ${ }^{[3]}$. Furthermore, nurses are marginalized in the society due to the nature of the tasks performed by them at health care settings such as bathing patients cleaning patients' vomits, stool, and urine, changing clothes, checking patients' genetalia, and handling their body parts. This nature of work has been considered as of lower category in some societies, therefore, nurses are disrespected and are considered less worthy in these societies; hence they are more prone to work related violence ${ }^{[4]}$. Moreover, it is easier to exhibit aggression and violent behaviors towards nurses because of their inferior repute among health care providers.

\subsection{Workplace Violence towards Nurses in Pakistani Society}

Why is workplace violence towards nurses in a Pakistani Society still a big question? According to my experience of working in the health care settings of Pakistan; Workplace violence is a devastating issue in Pakistan. The significant factor seems to be lack of respect towards the nursing profession in the Pakistani society. The other factors could be that Pakistan nurses are considered as oppressed group and this discrimination against the profession hinders nurses to get required respect and deliver high quality care in health care setting; hence impacting the overall health status of the nation badly ${ }^{[5]}$. Secondly, media has portrayed a very negative image of nurses in the society such as, symbols of sex and obedient servants of physicians. This Poor image of the profession is another contributing factor for workplace violence towards nurses ${ }^{[6]}$. Lastly, cultural imperialism is another significant factor with respect to violence towards nurses. In the private and public health sectors of Pakistan, nurses are still considered inferior and marginalized. Physicians and administrators are considered the dominant group in health care settings and quite often this dominant group exhibits aggression and violent behavior towards nurses. This frightens nurses at work place, created disrespect and disgrace towards this noble profession, and refrain young females from choosing nursing as a career ${ }^{[5]}$. Due to the high occurrence of this issue in the Pakistani society, nurses feel disrespected and dependent ,which hinders their autonomous decision making power, leads to further incompetencies and insecurities with respect to care of patients, and makes it extremely difficult for nurses to work for the benefit of patients.

\subsection{Characteristics of workplace violence towards Nurses}

Workplace violence towards Nurses can be categorized in two types: psychological violence and physical violence, and both these types of violence exist in different health sectors of Pakistan. Psychological violence can be further categorized into verbal violence, bullying, and sexual violence. Behaviors in psychological violence include: over friendly and sexualized attitude, lack of respect, intentional use of threatening language, violent gestures, threats, spreading of nasty rumors, engaging in abusive behaviors such as finger pointing, and offering unwanted sex ${ }^{[7]}$. Whereas, behaviors in 
Physical violence include: physical assaults or attacks, pushing, hitting, kicking, spitting, biting, punching, homicide, and rape ${ }^{[8]}$. Nurses often experience workplace violence from other nurses also, and this kind of violence is called horizontal violence. Behaviors in horizontal violence include: over dominating behavior, discrimination, excessive criticism of nurses without justification, exclusion or deliberate ignoring of nurses, undermining nurses' work by setting unrealistic deadlines or withholding key information, and blocking nurses' efforts to achieve promotion or any other kind of professional achievement ${ }^{[9]}$.

\subsection{Ethical aspects of workplace violence towards nurses}

The ethical aspects of workplace violence towards nurses are significantly important as nurses are expected to work for the wellbeing of human beings and, being advocates of patients, they fight for the rights and benefits of the patient. However, nurses' own rights are always compromised by others; although they are expected to fulfill their responsibilities ${ }^{[10]}$. Right is defined as a claim to anything which a person is allowed, such as power or opportunity. Responsibility is defined as being accountable or answerable to someone for something ${ }^{[11]}$. When society expects nurses to provide competent care with smiling a face, work under stressful conditions, and be loyal with the profession, then it is also the responsibility of each individual living in the society to provide respect to nurses and to their profession so they can work in a safe environment.

"The work of Freire (1972) and Fanon (1963) provided the theoretical underpinnings for the conceptualization of nurses as an 'oppressed group' they are inferior, less worthy and, eventually, 'fearful of freedom' Nurses have been considered an occupational group at considerable risk of violence-related workplace trauma” ${ }^{[12]}$. In earlier mentioned scenario, Ms. X experienced severe psychological trauma due to harassment by the patient and relative. When these kinds of scenarios at workplace are publicized by the media they prohibit young women from choosing nursing as a career. In Pakistan, the electronic and print media has recently communicated many pathetic scenarios of workplace violence towards nurses in private and government health care sectors. Besides these reported cases, there are many unreported cases in which nurses' have experienced rape, unwanted sexual deeds, workplace bullying, and physical violence from patients, their family members, and other paramedical staff; however, nothing significant has been done, yet, to overcome such unethical behaviors. "Nurses remain on the margins of the health care system with regard to power, autonomy, and respect in spite of increased educational preparation and expanded scope of practice ${ }^{[5]}$.

\subsection{Legal aspects of workplace violence towards nurses}

The legal aspects of workplace violence towards nurses are not yet considered as a policy matter at the organizational and country level; therefore, incidences of violence towards nurses are yet underreported because of fear and more disrespect in society, if formally reported. "There is a growing awareness that violence at work is not merely an episodic, individual problem but a structural, strategic problem rooted in wider social, economic, legal, organizational and cultural factors” ( ${ }^{[8]}$. Many countries have started working towards development of policies to overcome the issue of workplace violence towards nurses. In 2009 the Occupational Health and Safety Amendment act was introduced by the health ministry of Ontario and this act discussed legal perspective of all kinds of workplace harassment/violence in health care setting ${ }^{[9]}$.

Some health care settings in Pakistan, such as The Aga Khan University Hospital (AKUH) follows "zero tolerance” policy with respect to workplace violence; and according to policy the hospital does not tolerate the violent behavior of Patients, family members, visitors, and employees. This policy states that action against any kind of assault or affray will depends upon the nature and severity of the act ${ }^{[14]}$. Such policies prove organization commitment to provide safe and healthy workplace environment to their employees.In Pakistan different approaches are used to deal with workplace violence in different healthcare settings. Some healthcare organizations have no policy or rules for the legal implications for workplace violence; therefore, in the absence of such policies cases of violence and harassment are underreported in these organizations. In some health care settings, policies regarding workplace violence do exist but only for documentation and files purposes and as practical implementation is absent; neither the victims nor the perpetrators are aware about these policies. Therefore, incidences of workplace violence are high but under reported. However, some healthcare 
organizations strictly follow a zero tolerance policy for workplace violence and promote positive work place environment for nurses and other staff. Incidences of workplace violence towards nurses are comparatively low in these organizations.

In many health care organizations cases of workplace violence are under reported as nurses have fear that, they would be blamed by society for the act which happened at work with them. Moreover, reporting of such events may impact their marital and social life. This has been supported by Chaudhuri who conducted a study in Kalkata with 77 participants to assess workplace violence and harassment towards nurses ${ }^{[15]}$. He identified that in the healthcare sector nurses were experiencing terrible harassment but cases were under reported due to many reasons. Some participants stated that when they reported any kind of harassment, the management assessed their behaviors such that it made them victims of the event; moreover, confidentiality was exploited to such an extent that they felt, embarrassed to work as nurses; therefore they avoided reporting incidences. Other study participants said that due to lack of time and a busy schedule they did not report, and a few said that, verbal abuse was experienced by them many times in the entire day but they ignored it, as they knew that nothing would happen. A few female participants responded that many times, patients tried to touch their private parts while doing nursing tasks but they felt shame reporting it.

Like in other countries, dealing with workplace violence is always a challenging task for healthcare organizations in Pakistan also. Under reporting is the key issue in dealing with workplace violence. Governments should reinforce some legislation to promote a no violence culture within the healthcare settings.

\subsection{Consequences of workplace violence towards nurses}

Workplace violence towards nurses is very common in healthcare settings and this has consequences for nursing as a profession in Pakistan. Nurses who experience workplace violence suffer from many physical and psychological problems such as high stress or post-traumatic stress disorders, low self-esteem, low self-confidence, sleep disturbance, self-blaming, high stress and anxiety, and significant decline in performance at work. Eventually, they suffer from financial crisis due to absenteeism, and the financial burden increases considerably if they quit the job. ${ }^{[16]}$ Workplace violence in health care setting do affects the organization as well; such as loss of competent and trained nurses, decrease in nursing productivity, bad reputation of organization in society, legal issues related to security of employees, and wastage of time of human resources involved in resolving such issues. Overall, these consequences create an unsafe workplace environment in the country, which might significantly impact the overall health status of the nation.

\section{Discussion}

Workplace violence towards nurses is a devastating issue worldwide. It is very common in all small and big health care settings in the world. Mostly, incidences related to workplace violence are under reported due to a feeling of shame and guilt, lack of support from organizations, and lack of a structured system for reporting. Identification of contributing factors of workplace violence incidences is significantly important because, an understanding of the contributing factors will help health care organizations prevent workplace violence by implementing comprehensive programmes of reporting, preventing, and managing workplace violence. Additionally, it is extremely important to design effective strategies to assist nurses in dealing with workplace violence proficiently and competently.

\section{Recommendations at individual, organizational and country level}

Dealing with workplace violence towards nurses, is a challenging task for health care management. This part of the paper will provide some evidence (see Figure 1) based recommendations at individual, organizational and country level to deal with workplace violence towards nurses ${ }^{[17]}$. 


\section{Individual}

Appropriate preventive measures to reduce the risks of workplace violence

Timely report ing of the incident

Learning effective strategies to deal with workplace violence

Develop competencies to provide quality care topatients
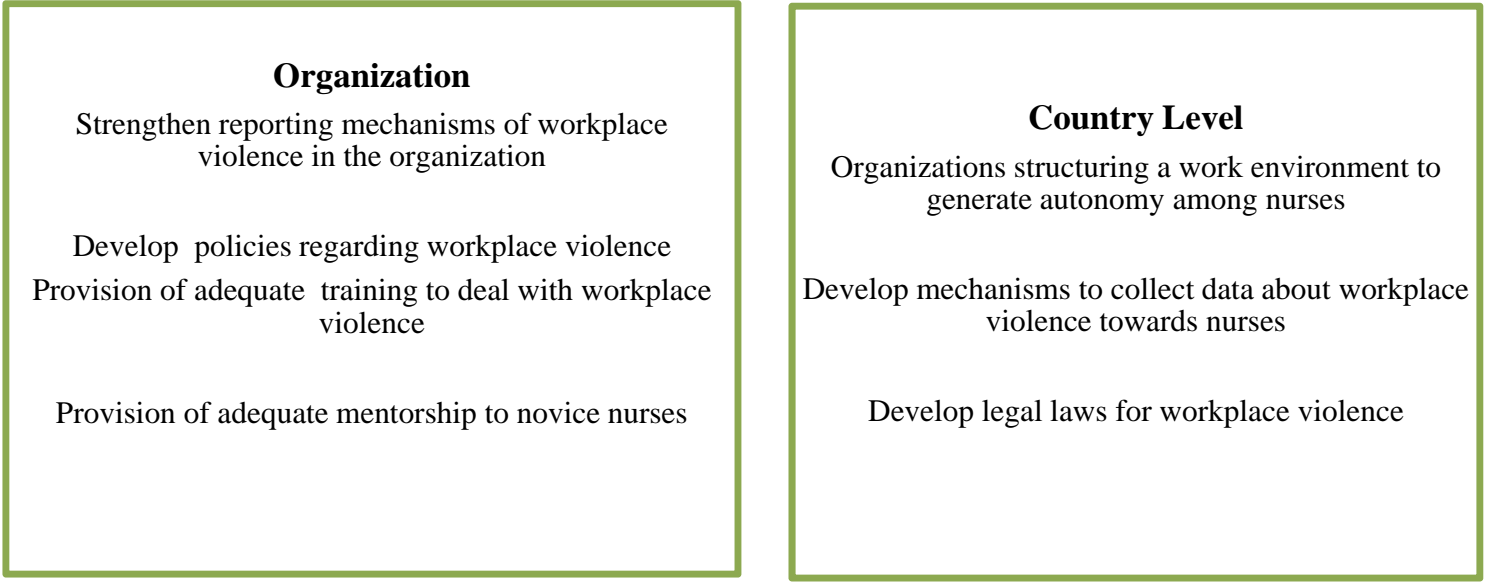

Figure 1. International Labour Office ILO, International Council of Nurses ICN, World Health Organization WHO, \& Public Services International PSI, 2002

\section{Conclusion}

Violence towards nurses in health care settings is a serious management issue. Nurses have the right to work in a safe environment and take autonomous decisions. All over the world organization management is facing challenges to provide a reasonable status to nurses in the society and to provide safe working environment to nurses. Literature reveals that the best tool to eliminate workplace violence is prevention. Employees should be informed about workplace violence policies at hiring level. Similarly, patients should be informed at admission level about the zero tolerance policy for violence. Comprehensive training program to recognize workplace violence and strategies to deal with it, will serve as strong weapons for nurses. Secondly, each individual working in a health care setting is responsible to report the incidents of workplace harassment. Management cannot make any strategic plan against workplace harassment unless and until it is reported by nurses working in the health care setting. Safe work environment will automatically attract nurses to remain in the nursing profession. 


\section{References}

[1] Registered Nurses’ Association of Ontario. Preventing and managing violence in the workplace [Internet]. 2009. Available from: http://www.rnao.org/Storage/61/5519_RNAO_Violence_in_work_WEB_2.pdf

[2] Hutton, S.A. Workplace incivility. The Journal of Nursing Administration. 2006; 36(1); 22-28. http://dx.doi.org/10.1097/00005110-200601000-00006

[3] Lin, Y. H., Liu, H. E. The impact of workplace violence on nurses in South Taiwan. International Journal of Nursing Studies. 2005; 42: 773-778. PMid:15964004 http://dx.doi.org/10.1016/j.ijnurstu.2004.11.010

[4] Bronner, G., Peretz, C., Ehrenfeld, M. Sexual harassment of nurses and nursing students. Journal of Advanced Nursing. 2003 ; 42 (6): 637-644. PMid:12787237 http://dx.doi.org/10.1046/j.1365-2648.2003.02667.x

[5] Lee, B., Saeed, I. Oppression and horizontal violence: The case of nurses in Pakistan. Nursing Forum Volume. 2001; 36(1): 15-24. http://dx.doi.org/10.1111/j.1744-6198.2001.tb00236.x

[6] French, S. E., Watter, D., Matthews, D. R. Nursing as a career choice for women in Pakistan. Journal of Advance Nursing. 1994; 19: 140-150. PMid:8138618 http://dx.doi.org/10.1111/j.1365-2648.1994.tb01062.x

[7] Randle, J. Bullying in the nursing profession. Journal of Advanced Nursing. 2003; 43 (4): 395-401. PMid:12887358 http://dx.doi.org/10.1046/j.1365-2648.2003.02728.x

[8] International Labour office. Workplace Violence: A new global problem. World of work. 1998; 1-36.

[9] Roche, M., Diers, D., Duffield, C., Paul, C. Violence towards nurses, the work environment, and patient outcomes. Journal of Nursing Scholarship. 2010; 42: 13-22. PMid:20487182 http://dx.doi.org/10.1111/j.1547-5069.2009.01321.x

[10] Grace, P., Gaylord, N. Nursing advocacy: An ethics of Practice. College of Nursing, Knoxville, TN, USA. 1995 ; 2 (1): $11-18$.

[11] Flynn, D. What's wrong with rights? Rethinking human rights and responsibilities. Australians social work. $2005 ; 58$ (3): $44-256$.

[12] Hutchinson, M., Vickers, M., Jackson, D., Wilkes, L. Workplace bullying in nursing: Towards a more critical organizational perspective. University of Western Sydney. 2005; 2(5).

[13] Rebecca, A., Esq, S. Workplace violence: A legal perspective. Occupational Environmental Medicine. 2003 ; 3: $733-745$. http://dx.doi.org/10.1016/S1526-0046(03)00121-3

[14] Aga Khan University Hospital. Zero tolerance policy [Internet]. Retrieved on October. 2010. Available from; http://intranet/jcia/

[15] Chaudhuri, P. Sexual harassment in the workplace experiences of women in the health sector. Health and population innovation fellowship programme working Paper. 2006.

[16] Jackson, D., Clare, J., Mannix, J. Who would want to be a nurse? Violence in the workplace - a factor in recruitment and retention. Journal of Nursing Management. 2002; 10: 13-20. PMid:11906596 http://dx.doi.org/10.1046/j.0966-0429.2001.00262.x

[17] International Labour Office ILO, International Council of Nurses ICN, World Health Organization WHO, \& Public Services International PSI. Framework Guidelines for addressing workplace violence at health sectors [Internet]. 2002. Available from: http://www.who.int/violence_injury_prevention/violence/activities/workplace/documents/en/index.html 